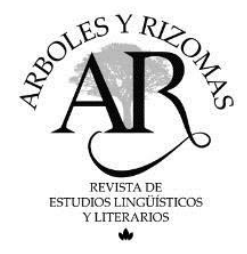

Árboles y Rizomas Vol. II, No 1 (enero-junio, 2020): 19-32

Universidad de Santiago de Chile, ISSN 0719-9805

https://doi.org/10.35588/ayr.v2i1.4103

\title{
Una selva de voces y sonidos
}

\author{
A jungle of voices and sounds
}

\author{
Fernando Moreno ${ }^{1}$
}

\begin{abstract}
Resumen
Después de recordar algunas de las lecturas que se han realizado de la célebre novela de José Eustasio Rivera, este artículo se orienta hacia la presentación y determinación de sentido de la selva de voces que se despliega en la obra. Para esto, nos situamos más bien en el nivel del espacio textual y en la cadena de incesantes lecturas de la que ha sido objeto La vorágine. Se quiere destacar cómo el protagonista Arturo Cova integra, interpreta y transcribe en sus discursos y en su escritura, las voces, las visiones del mundo de los demás personajes, de los otros hablantes y de otros textos. De este modo, y gracias a la labor del narrador, que es auditor y escriba, se concreta un intrincado y laberíntico espacio discursivo, una vorágine de voces, comparable al propio espacio selvático desplegado en la novela, y en el que hasta el mínimo detalle significa.
\end{abstract}

Palabras clave: Novela hispanoamericana, J. E. Rivera, La vorágine, selva, voces.

\begin{abstract}
Upon recalling some of the readings about the famous novel by José Eustasio Rivera, this article focuses on the presentation and how the meaning of the jungle of voices that unfold in the text is constructed. For this purpose, we place ourselves at the level of the textual space and in the chain of incessant readings of which $L a$ vorágine has been the object. We want to highlight how the protagonist Arturo Cova integrates, interprets and transcribes the voices, the worldviews of the other characters, of the other speakers and of other texts in his discourse and writing. In this way, and thanks to the work of the narrator, who is an auditor and a writer, an intricate and labyrinthine discursive space is realized, a vortex of voices, comparable to the jungle space itself displayed in the novel and in which even the smallest detail conveys meanings.
\end{abstract}

Key words: Spanish-American novel, J. E. Rivera, La vorágine, jungle, voices.

1. Fernando Moreno, Profesor Emérito. Centre de Recherches Latino-Américaines Archivos, Université de Poitiers, Francia. Correo electrónico: fmorenoturner@gmail.com 


\section{Introducción}

Es indudable que la representación del espacio es uno de los aspectos que más ha llamado la atención de lectores, críticos y estudiosos de La vorágine. La presencia y los efectos de aquel "infierno verde" no sólo son perceptibles en el nivel interno, el de la intriga y de los avatares de los personajes, también lo han sido en el nivel de la lectura, de la consideración e interpretación de la novela de José Eustasio Rivera y de algunas otras similares manifestaciones de la narrativa continental.

La última y celebérrima frase de la novela -“iLos devoró la selva!”2- parece condensar el peso determinante del papel de una apabullante naturaleza en la concepción y en la construcción de mundos narrativos en los que la dimensión espacial contribuye a la expresión primordial de determinados signos considerados como identitarios de América Latina. Así, por ejemplo, Carlos Fuentes (1969), en uno de sus más conocidos ensayos sobre nuestra narrativa señala, al comentar el papel protagónico asumido por la naturaleza, el carácter paradigmático de aquella afirmación con la que termina la obra de Rivera. El autor mexicano, que sin duda acude solo a su memoria, transforma la citada frase de la novela de Rivera en "se los tragó la selva":

La exclamación es algo más que la lápida de Arturo Cova y sus compañeros: podría ser el comentario a un largo siglo de novelas latinoamericanas: se los tragó la montaña, se los tragó la pampa, se los tragó la mina, se los tragó el río. Más cercana a la geografía que a la literatura, la novela de Hispanoamérica había sido descrita por hombres que parecían asumir la tradición de los grandes exploradores del siglo XVI. Los Solís, Grijalva y Cabral literarios continuaban, hasta hace pocos años, descubriendo con asombro y terror que el mundo latinoamericano era ante todo una presencia implacable de selvas y montañas a una escala inhumana (p. 9).

Sin embargo, la frase final de La vorágine también puede ser considerada como un excelente comentario y caracterización de una gran parte de la recepción crítica de la que ha sido objeto la obra; incluso podría decirse que a muchos de sus lectores, profesionales o no, también los engulló la selva y todo el distorsionado espacio social que bulle en ella.

En efecto, y tal vez no podía ser de otra manera, la lectura tradicional o canónica de $L a$ vorágine insistirá fundamentalmente en destacar dos aspectos. Por una parte, el carácter documental o de testimonio que posee la narración y, por lo tanto, su valor de denuncia de las condiciones de trabajo de los caucheros colombianos en las zonas selváticas fronterizas; por otra, el singular retrato y representación de la naturaleza, esto es, la dimensión mítica y el telurismo épico-lírico que resulta de la fuerza y magnitud concedidas al espacio selvático por el discurso narrativo.

De hecho, tales opciones de lectura tienen en gran parte asidero en un conocido comentario del escritor uruguayo Horacio Quiroga quien, en 1929, en una nota escrita con motivo del fallecimiento de Rivera indicó, por ejemplo, que

La vorágine es eso, por encima de sus grandes calidades: un inmenso poema épico, donde la selva tropical, con su ambiente, su clima, sus tinieblas, sus ríos,

\footnotetext{
2 José Eustasio Rivera, La vorágine, Madrid, Cátedra, 1990 [Edición crítica de Monserrat Ordóñez, Letras Hispánicas n³15], p. 385. Todas las citas se hacen por esta edición. La obra fue publicada por primera vez en 1924.
} 
sus industrias y sus miserias, vibra con un pulso épico no alcanzado jamás en la literatura americana. [...] Pero si el hombre de temple se detuvo entre el Isana y el Guainía, junto al Guaracú, jugando su nombre y su vida a la redención de unos cuantos miserables, su temple de artista abarcó el trópico entero, para lanzar, por decirlo así, a los ojos mismos del lector, el panorama inmenso, torrentoso, mefítico y nefasto de la hoya amazónica. [...] La pasión de los personajes, la pasión de la selva y de la acción misma laten con tan cruda vida que no es indispensable haber apurado nunca el vaho de la selva para sentirla remontar hasta las mismas narices. Se respira selva: tal es el soplo épico de su evocador, y tal la energía de su expresión ${ }^{3}$.

Un gran sector de la crítica compartió el enfoque allí proporcionado y ha seguido reincidiendo en considerar prioritariamente los rasgos señalados por el autor de los Cuentos de amor, de locura y de muerte, un título que, por lo demás, también convendría a la novela de José Eustasio Rivera. Además, es sabido que tales características convirtieron a La vorágine en una de las obras regionalistas y "terrígenas" por excelencia" y en la "novela de la selva" por antonomasia ${ }^{5}$. Todo lo cual no puede sino resultar innegable, pero es también indiscutible que el hecho de limitarse a dichos aspectos no puede sino contraer y reducir las dimensiones significativas y los alcances estéticos de su discurso narrativo.

Así lo entendió también otra parte de la crítica, representada por Germán Espinoza (2000), por ejemplo, la que consideró que el texto no podía ser visto únicamente como el paradigma de la representación del papel de la naturaleza hostil o como un ejemplar discurso literario de denuncia social, sino además, como un insospechado fenómeno de renovación estética. De hecho, tal como lo había demostrado Monserrat Ordóñez, existe una evolución significativa en el proceso de recepción crítica de la obra, recepción que ha comenzado por un interés acentuado hacia la comparación entre la historia y la ficción, para llegar a lecturas que problematizan el texto desde la perspectiva de las interrelaciones culturales, pasando por etapas de canonización, de abordajes estructurales y de estudios de nuevas perspectivas a propósito de la naturaleza y de los rasgos singulares del personaje protagónico ${ }^{6}$.

Las múltiples lecturas y relecturas han puesto en evidencia la complejidad y la riqueza de La vorágine, así como los múltiples estratos en los cuales puede centrarse un análisis de la misma, sin que por eso pueda considerarse, como sucede con las auténticas obras literarias, que se haya dicho todo o casi todo sobre ella. Así lo puso en evidencia, por ejemplo, J. Walker (1988), quien en un sugerente y extenso estudio sobra la obra, se propuso examinar los aspectos ligados a la representación espacial, a la dimensión social, al nivel psicológico, a los niveles

\footnotetext{
${ }^{3}$ Horacio Quiroga, "El poeta de la selva: José Eustasio Rivera", La Nación, Buenos Aires, 22 de enero de 1929, pp. 17-18. También en Repertorio Americano, San José, Costa Rica, XIX, 3, 20 de julio de 1929, p.40. Reproducido en Monserrat Ordóñez, La vorágine: Textos críticos, Bogotá, Alianza Editorial, 1987, pp. 78-81.

${ }^{4}$ De ahí, por ejemplo, la obligada inclusión de La vorágine, junto con Don Segundo Sombra y con Doña Bárbara, en los capítulos dedicados al realismo y al regionalismo en los textos de historiografía literaria. Véanse, entre otros, Fernando Alegría (1966, pp. 180-204), Giuseppe Bellini (1986, pp. 502-513), Jean Franco (1987, pp. 181-220), Luis Sáinz de Medrano, (1989, pp. 191-207), Marina Gálvez, (1990, pp. 160-193), José Miguel Oviedo (2001, pp. 225248).

${ }^{5} \mathrm{Al}$ respecto puede consultarse el documentado y ahora clásico estudio de Lydia de León Hazera (1971) citado en la Bibliografía.

${ }^{6}$ Cf. Monserrat Ordóñez, "Introducción”, en José Eustasio Rivera, La vorágine, op. cit., pp. 16-20. Esta historia de la crítica sobre la novela de Rivera se halla ejemplificada en la valiosísima e indispensable y ya citada recopilación realizada por la propia Monserrat Ordóñez, publicada bajo el título de La vorágine: Textos críticos (1987).
} 
míticos y arquetípicos, a la expresión de ciertos valores asociados con la búsqueda de ideales y, por último, a determinados aspectos de la estructura narrativa. Ahí Walker señala que:

[t]o demonstrate that, like all great art, it can be read at, and does operate at, various levels, I intend to dismantle it, as it were, to highlight its various dimensions or planes -regionalist-nature, social protest, psychological, mythological-archetypal, search for values and ideals- then reconstruct it by linking the parts and putting them all together again (1988, pp.11-12).

Ahora bien, teniendo en consideración lo recién expuesto, queremos formular aquí algunas breves observaciones que contribuyan a consolidar esta cadena de incesantes y nuevas lecturas de La vorágine que la propia novela solicita y merece, manteniéndonos en el nivel de la representación del espacio, pero considerándolo desde una perspectiva que excede el mero intento de descripción y de recreación de un paisaje, orientándonos más bien hacia la presentación del espacio textual, o de lo que hemos llamado la selva de voces que se despliega en la obra.

\section{La espacialización en La vorágine}

Es indudable que, en todo texto literario, los personajes y los objetos adquieren una determinada dimensión y una clara consistencia cuando aparecen enmarcados, situados y concebidos en un espacio y en un tiempo determinados. El narrador procede a la creación verbal de un espacio imaginario en el que se mueven, en ciertas situaciones, los personajes de una historia, un espacio imaginario que puede poseer y que puede concretarse en varios niveles.

En efecto, el término espacio presenta una gran amplitud semántica y puede referirse, por ejemplo, tanto a sitios o lugares precisos y específicos, a veces identificables, en los cuales se produce una situación dada, así como a la dimensión simbólica o a la atmósfera, al talante ético o espiritual al que la obra alude. Pero, y por ello mismo, también se puede hablar no sólo de un espacio referido o significado, sino de un espacio significante ${ }^{7}$. En este caso se trata del espacio del relato cuyos límites se precisan en la voluntad constructiva del texto y, por lo tanto, en las relaciones entre hablante implícito, narrador y destinatario, por ejemplo, así como en los procedimientos discursivos y técnicas que modulan y posibilitan singulares caracterizaciones de los personajes, que determinan elaboraciones de la temporalidad y de modos narrativos, que proponen inclusiones de otras manifestaciones textuales, que orientan hacia la trama y hacia el entramado del propio quehacer discursivo.

No es nuestra intención referirnos aquí en detalle a los niveles espaciales significados. Baste recordar, en un primer momento, que el marco espacial -que implica las notaciones de tiempo histórico y lugar geográfico en que transcurren los acontecimientos, así como el estrato o ambiente social donde se mueven, se desenvuelven o al cual pertenecen los personajes- no es demasiado difícil de determinar en la medida en que el texto va precisando, de acuerdo con el peregrinaje de Arturo Cova, nombres de lugares, zonas, pueblos y ríos. Tales indicaciones permiten incluso situar con mayor o menor certeza el itinerario del personaje en un mapa bastante

\footnotetext{
${ }^{7}$ Según la distinción establecida por Gérard Genette en "La littérature et l'espace", en Figures II, Paris, Seuil, 1969, pp. $43-48$.
} 
preciso $^{8}$. Este marco espacial, que funciona en relación con el sentido de denuncia y testimonio que posee el texto, formula prioritariamente toda una serie de referencias a la explotación del caucho en la región amazónica, a las exacciones cometidas por la Casa Arana, filial de The Peruvian Amazony Company, y por quienes, como el gobernador Funes -cuya historia, apegada a la realidad histórica cuenta Ramiro Estévanez-, disponen de un derecho de vida y de muerte por sobre los caucheros 9 .

Ahora bien, y volviendo someramente a ese espacio significado, es sabido que los escenarios de La vorágine se sitúan prioritariamente en los llanos y en la selva, y que esta última es presentada, representada, la mayor parte de las veces por medio de pasajes descriptivos, a veces evaluativos, los que incluso pueden poseer intensas tonalidades líricas, como sucede, por ejemplo, en los pasajes llamados "canto de la selva" y el "lamento del cauchero", que constituyen los fragmentos iniciales de la segunda y de la tercera parte de la novela (pp. 189-190; 287-289). Mediante dichas descripciones y su particular adjetivación, gracias a la disposición de los personajes y demás elementos en el escenario, mediante la puesta en evidencia de la afluencia de estímulos sensoriales -sensaciones visuales, auditivas, olfativas, por ejemplo-, se va creando una atmósfera, un ambiente que asume un papel condicionante de determinados modos de conducta, de rasgos sicológicos, un espacio que cumple funciones que connotan formas de vida, creencias y esquemas de valores ${ }^{10}$.

De ahí que la espacialización vaya constituyendo esa imagen densa de la selva, vaya desplegando un complejo escenario en el que se confunden rechazo y seducción, vaya construyendo un espacio inhumano y deshumanizado, envolvente, máscara de la vida y rostro de la muerte, porque la selva es cárcel, fuerza inhalante, abismo antropófago, espacio antropomórfico, ambiente hostil que aniquila al ser. La selva en La vorágine es, además, el espacio cósmico, un magma vegetal, en ese manto protector, en esa manta gigante que engulle y que frustra cualquier posibilidad de salvación, como no sea la del propio testimonio de la escritura.

\section{El espacio significante: la intertextualidad}

Como es sabido, a medida que avanza la narración, los personajes se van adentrando en el laberíntico espacio selvático. Por medio de este periplo comienza a proyectarse la configuración de otro nivel espacial, el que aparece modulado por distintas manifestaciones de la intertextualidad, por los ecos de otras voces, por las huellas de otras escrituras que vienen a inscribirse en el discurso de la novela.

En efecto, y sin hablar de los sustratos románticos, modernistas y simbolistas que suelen insinuarse en el discurso del narrador, rastreados por Edmundo de Chasca (1987) o por Otto Olivera (1987), entre otros, varios estudiosos ya han destacado la presencia de un significativo conjunto de reminiscencias literarias. Entre ellas, por ejemplo, destaca un correlato, el que tiene como eje el motivo del "descenso a los infiernos", cuyos antecedentes clásicos -La Odisea de

\footnotetext{
${ }^{8}$ Véase la "Ruta de Arturo Cova" en José Eustasio Rivera, La vorágine, edición de Monserrat Ordóñez, ed. cit. p. 386.

${ }^{9}$ El "coronel" Funes es el responsable de una matanza ocurrida en mayo de 1913; fue fusilado en 1921. La llamada "fiebre del caucho" y las condiciones inhumanas de explotación de los gomeros ocasionaron numerosos informes, investigaciones y denuncias nacionales e internacionales. Para mayores informaciones sobre estos aspectos puede consultarse el libro de Eduardo Neale-Silva (1986), así como el artículo de Roberto Simón Crespi (1987).

${ }^{10}$ No insistiremos aquí sobre estos factores y dimensiones que ya han sido formulados y explicitados por la crítica, en particular en el excelente análisis de la novela realizado por Françoise Perus (1998, pp. 117-222).
} 
Homero, La Eneida de Virgilio y la Divina Comedia de Dante- son conocidos y cuya estructura y componentes pueden ser rastreados directa e indirectamente en el itinerario del narrador de La vorágine. Así, Leónidas Morales (1965) demostró con acierto las equivalencias existentes entre determinados elementos del Canto VI de La Eneida y aquellos que, transformados, forman parte del relato de Arturo Cova. Ellos son la laguna o río Estigio, con sus aguas sombría y tétricas, la barca de Caronte - la "curiara"- en la que se cargan y se transportan las almas de los muertos, el espacio de la orilla opuesta, esto es, el lugar donde la barca deposita su carga, el guía -en La vorágine, don Rafo y, en especial, Clemente Silva- que orienta y conduce al viajero y, en último lugar, el espacio de destino, el infierno, el tenebroso dominio de la selva.

Por su parte, Seymour Menton (1987) insistió sobre todo en la importancia de la obra de Dante en la estructura básica de La vorágine. Para él, la novela de Rivera es una suerte de réplica a la Divina comedia. Si en ésta, el poeta peregrino Dante, después de haber iniciado su viaje por el bosque infernal, asciende hasta llegar al Paraíso, "Arturo Cova baja del Paraíso de la cordillera, por ambiguo que sea, y no cesa de dar vueltas hasta caer irredento a la sima sin fondo de la selva infernal" (p. 199). Además del itinerario general recién esbozado, otros detalles de la novela del colombiano tienen, para el crítico recién citado, antecedentes en los diferentes cantos del Purgatorio y del Infierno dantescos: la imagen del águila que vuela cerca del sol, la relación y la transformación de los hombres en árboles, por ejemplo.

Evidentemente, no son esas obras los únicos discursos que conformarían el nivel de espacio intertextual de la novela. Por lo demás, y con justa razón, algunos estudiosos han establecido e insistido en la innegable presencia del sustrato mítico americano en la novela, en particular con la incorporación de la leyenda de la indiecita Mapiripana, así como otros pertenecientes a las cosmovisiones amerindias, elementos que, junto con instaurar un diálogo intratextual e intercultural, desempeñan significativas funciones estructurales y compositivas (Gómez, 2008; Mateo, 1988; Velasco, 1995).

Desde otra perspectiva también se ha señalado, como lo hiciera Alfonso González (1987), que pueden establecerse ciertos nexos entre el modo de actuar de Arturo Cova y el comportamiento del héroe de Cervantes, Don Quijote. Incluso, en una nueva lectura de la obra, para Leónidas Morales (1992) -y a pesar de ciertas evidentes y lógicas diferencias-, las aventuras relatadas, los motivos fundamentales, la construcción de la intriga y determinados niveles de indeterminación de la realidad presentes en la novela de Rivera, no pueden sino recordar situaciones modélicas del género caballeresco:

Aun cuando el llano y la selva como espacio de las acciones de La vorágine, tienen una identidad perfectamente determinada en la geografía de América, y los personajes en general no son extraños a la verosimilitud de lo real, revelan, sin embargo, dimensiones que no existen en Cervantes y que en cambio evocan el mundo encantado de los relatos caballerescos medievales: la magia, el misterio, el aura de lo onírico y lo fantástico. Sólo el horror de la selva es ajeno a esos relatos (p. 81).

Pero, además de los recién evocados, la crítica especializada ha detectado muchos otros intertextos, y otras fuentes que pueden haber contenido o de las cuales pueden haber surgido los materiales básicos para la construcción de ese espacio discursivo: son otras filiaciones, una madeja de fibras literarias que convierten la narración de Arturo Cova en un densísimo tejido textual. Así, por ejemplo, Rafael Gutiérrez Girardot (1994) afirma que 
Rivera logró fundir las tradiciones de la literatura de viajes [...], el costumbrismo hispanoamericano en la versión crítico-sociológica del Facundo [1865] de Sarmiento y de su más cercano autor, Eugenio Díaz Castro con su Manuela [1866], el exotismo europeo en sus ecos hispanoamericanos, difundidos por Andrés Bello en su "Silva a la agricultura de la zona tórrida" [1826] con la tradición de la elegía de la poesía amorosa (Virgilio, Propercio) y de las novelas de artistas (Ídolos rotos [1901] de Manuel Díaz Rodríguez, por ejemplo), y en una prosa artística que tiene su antecedente remoto en la llamada "latinidad de plata" y el más próximo y eficaz en la de José Enrique Rodó y su Ariel (1900) (p. 118).

Podrían también traerse a colación otros textos y otros discursos, los del colombiano José Asunción Silva -De sobremesa. 1887-1896- e incluso los del propio José Eustasio Rivera, es decir los poemas de Tierra de promisión (1921), sin olvidar por cierto obras tales como María de Jorge Isaacs (1867), como lo destacó Françoise Perus (1988), u otros relatos en los que el espacio de la selva desempeña un papel significativo (como sucede en los cuentos del ya evocado Horacio Quiroga, por ejemplo).

De este modo el peregrinaje de Arturo Cova y de los demás personajes por esa selva se convierte en un constante vaivén, en un movimiento de ida y vuelta hacia aquellos textos, pero además en un incesante recorrido por otras voces que son convocadas por el narrador protagonista. De acuerdo con lo cual se hace presente aquí otra dimensión espacial, la configurada por los múltiples discursos y escrituras que están en el texto, que son el texto y/o los textos redactados por Arturo Cova, los que a su vez se insertan en aquel marco más amplio constituido por el "Prólogo" y el "Epílogo" que aparecen bajo la firma de José Eustasio Rivera.

\section{"Tus multísonas voces forman un solo eco"}

Existe entonces un autor ficcionalizado, quien se presenta como el responsable de la transcripción de los "manuscritos" entregados por el Cónsul de Colombia en Manaos al Ministro a quien se dirige ese autor-editor (p. 75). Ese mismo personaje es también quien ha introducido la explicación final, con la que se cierra el conjunto textual y en la que se reproduce el cable del funcionario consular que informa sobre la desaparición de Arturo y sus acompañantes. Al nivel de este marco narrativo pertenece también el "Fragmento de la carta de Arturo Cova" (p. 77) presentado inmediatamente después del prólogo y que el personaje escribiera en las barracas del Guaracú y que el propio narrador compara con una suerte de torbellino: es el pliego que debía llevar Clemente Silva, "una tremenda requisitoria, de estilo borbollante y apresurado como el agua de los torrentes" (p. 343).

El recurso a la voz y a la escritura "autoriales", cuya función básica es la de orientar hacia la consideración de la veracidad de lo narrado implica además la imposibilidad de identificación de la voz de Rivera con la de Cova y, por lo tanto, una primera manifestación de la incorporación de diálogos y de la confrontación de voces y alteridades, fenómeno que constituye una de las bases de este espacio significante y el punto de arranque de la devorante escritura de Arturo Cova.

La estructura y estructuración del singular marco narrativo de La vorágine ya ha sido estudiada por diversos críticos, así como la presencia de numerosos relatos intercalados en la narración de Arturo Cova, aunque, en algunos casos, ésta ha sido considerada como una falla en la composición de la novela en la medida en que, además de ser un procedimiento demasiadas 
veces reiterado, rompe el ritmo de la aventura y de la acción centrales ${ }^{11}$. Lo que además se ha destacado, aunque no de manera suficiente, es que el relato de Arturo Cova emerge de una precisa pero extremadamente compleja situación enunciativa en lo que concierne sus condiciones, propósitos y orientaciones:

Va para seis semanas que, por insinuación de Ramiro Estévanez, distraigo la ociosidad escribiendo las notas de mi odisea, en el libro de Caja que el Cayeno tenía sobre su escritorio como adorno inútil y polvoriento. Peripecias extravagantes, detalles pueriles, páginas truculentas forman la red precaria de mi narración, y la voy exponiendo con pesadumbre, al ver que mi vida no conquistó lo trascendental y en ella todo resulta insignificante y perecedero.

Erraría quien imaginara que mi lápiz se mueve con deseo de notoriedad [...] No ambiciono otro fin que el de emocionar a Ramiro Estévanez con el breviario de mis aventuras, confesándole por escrito el curso de mis pasiones y defectos, a ver si aprende a apreciar en mí lo que en él regateó el destino y logra estimularse para la acción [...] yo sí puedo enseñarle mis huellas en el camino, porque si son efímeras, al menos no se confunden con las demás. Y tras demostrarlas quiero describirlas, con jactancia o con amargura, según la reacción que producen en mis recuerdos, ahora que las evoco bajo las barracas del Guaracú (pp. 345-346).

La versatilidad, la ironía, la paradoja, la afectación, la autocrítica, la inadaptación que se derivan de estas consideraciones no son sólo ecos de la contradictoria figura del narradorprotagonista -el poeta meditativo e histriónico, débil y colérico- y de sus constantes arrebatos emocionales, de su vorágine interior, de su relación consigo mismo, también lo son de los complejos vínculos que Cova mantiene con la escritura, de donde surgen los aspectos reflexivos y metadiscursivos de la novela, destacados por Jaime Martell (1999), y con las voces de los demás personajes que va integrando a su propio quehacer discursivo.

La presencia autorial de Cova pareciera desmoronarse, rompiéndose la unicidad no sólo por la incorporación de otros relatos, sino por la configuración de un denso tejido linguiístico en el que participan tanto una diversidad de estilos literarios como una multiplicidad de dialectos e idiolectos; éstos construyen el entramado heteroglósico de un mundo forjado por las condiciones sociales, históricas, culturales, étnicas de aquellos innumerables personajes que Arturo Cova va conociendo a lo largo de su periplo o que lo van acompañando en su viaje fatal por ese infierno verde.

Como es sabido, el concepto de heteroglosia, que implica la participación de varias voces en el seno de un discurso, fue acuñado por Mijaíl Bajtín (1982, 1989, 2012) y alude, en un primer nivel, al diálogo que, en el propio nivel del lenguaje, se instaura en lo individual, lo discursivo y lo ideológico. Como se puede apreciar a través de lo reseñado hasta ahora, en La vorágine se concreta un complejo dialogismo cultural, en el que participan tanto factores relativos a su referencialidad (los estratos políticos, sociales, étnicos, genéricos allí consignados), como a su discursividad, en la medida en que la voz y la escritura de Cova convocan todo ese cúmulo de textos a los que se ha aludido aquí. De ahí que Alejandro Mejías-López pueda asegurar que la obra de Rivera "va reconstruyendo una genealogía de la explotación y sus discursos legitimadores para simultáneamente ir deconstruyéndola, ofreciendo así una reflexión crítica

\footnotetext{
${ }^{11}$ Sobre la construcción narrativa véanse, entre otros, Joan R. Green (1967), Juan Loveluck (1968), Silvia Benso, (1975), Ernesto Porras Collantes (1968), Richard Ford (1976), Sylvia Molloy (1987), Eduardo Thomas (1991).
} 
sobre el poder y las trampas del lenguaje de la modernidad" (2006, p. 370), como un conjunto hecho de voces dentro de voces, de discursos dentro de discursos que "van construyendo la selva como un espacio textual" (387).

En realidad, Arturo Cova integra, interpreta y transcribe en su voz, en sus distintas tonalidades y matices (reflexiones, alabanzas, delirios, sueños, fantasías) y en su escritura (su carta y su texto), las voces, las visiones del mundo de los demás personajes y hablantes. De este modo, y gracias a la labor del narrador, que es necesariamente auditor y escriba, se concreta un intrincado y laberíntico espacio discursivo, una vorágine de voces, comparable al propio espacio selvático, tal como lo concibe y lo refiere una de las facetas enunciativas del propio personaje:

Tú eres la catedral de la pesadumbre, donde dioses desconocidos hablan a media voz, en el idioma de los murmullos, prometiendo longevidad a los árboles imponentes, [...] Tus multísonas voces forman un solo eco al llorar por los troncos que se desploman, y en cada brecha los nuevos gérmenes apresuran sus gestaciones. Tú tienes la adustez de la fuerza cósmica y encarnas un misterio de la creación. (pp. 189-190).

Un somero recuento de la labor de audición y transcripción de Arturo Cova permite deslindar diversas estrategias y reconocer la amplitud de la tarea y del resultado. Así conviene recordar que, por ejemplo, Cova escucha los consejos "inolvidables" de Don Rafo (p. 96); que el mulato Correa le relata sucesos concernientes a Franco narrados a su vez por Helí Mesa en cuanto "testigo presencial" (p. 169); que escucha el "mendoso discurso" del Pipa (p. 182) y la "pavorosa serie de sus andanzas" (p. 196) y que, sentado "en el suelo, hundida la cabeza entre las rodillas" (p. 218), hace lo mismo con el brutal relato de Helí Mesa y luego con la historia de la indiecita Mapiripana (p. 225), sin olvidar su particular recepción de la confesión de Franco, pues dice a propósito de ella "No guardo otra memoria de su discurso: aunque lo oía, no lo escuchaba" (p. 236). Luego vendrán las trágicas historias de Clemente Silva (p. 251 y siguientes) y el terrible testimonio de Ramiro Estévanez (pp. 347-355).

Pero, además, en su narración, Arturo Cova transcribe directamente los diálogos con los demás personajes, o bien intercala diálogos en los relatos de los otros narradores. Con bastante frecuencia, el protagonista, antes de describir o de narrar acciones, pone en evidencia su estatuto de testigo y sobre todo de oyente (p. 111, por ejemplo), y reproduce en los diálogos insertos las variantes dialectales y las hablas regionales de los distintos personajes, sin olvidar de aludir, en ciertos momentos, a los estilos y la manera de expresarse de los demás personajes. En este último sentido recuérdese por ejemplo que el narrador destaca el "acento cálido" de la niña Griselda (p. 110), la "voz carrasposa" del viejo Zubieta (p. 140), o el "tono de amante" del discurso del Pipa (p. 182), entre otros muchos casos.

Arturo Cova interviene con frecuencia en las historias "intercaladas" -que, en definitiva, entonces no lo son- y en determinados momentos interrumpe los relatos que escucha para obtener informaciones complementarias que considera necesarias o bien trata de orientar y de aconsejar a los narradores sobre la manera cómo deben continuar con la tarea enunciativa. Así, por ejemplo, dirigiéndose al anciano Silva le dice "-Don Clemente: no resucite esos recuerdos que hacen daño. Procure omitir en su narración todo lo sagrado y lo sentimental. Háblenos de sus éxodos en la selva" (p. 253).

En otras ocasiones la participación de Cova es todavía más significativa, puesto que de la interrupción pasa a la asimilación y a la apropiación de los discursos "ajenos" y, por ende, de sus 
experiencias. Es lo que sucede con el fragmento inicial de la tercera parte, el llamado lamento del cauchero, o con el relato de una de las aventuras de Clemente Silva en el siringal de Yaguanarí:

-Tengo presentes los pormenores. Cuando su fuga para el Vaupés...

-Éramos siete caucheros prófugos.

-Y quisieron matarlo...

-Creían que los extraviaba intencionalmente.

-Y unas veces lo maltrataban...

-Y otras me pedían de rodillas la salvación.

-Y lo amarraron una noche entera...

-Temiendo que pudiera abandonarlos

-Y se dispersaron por buscar el rumbo...

-Pero sólo toparon el de la muerte (p. 300) ${ }^{12 .}$

El poeta Cova escucha sus propias voces, escucha las voces de la selva y las voces de los otros. Con estos materiales modula, interpreta organiza y escribe una historia hecha de historias, una historia que puede ser diversamente considerada ("una historia fútil y montaraz", dice el narrador p. 373), una historia necesaria, aunque parcial, porque no contiene todos los datos pertinentes ("Son la historia nuestra, la desolada historia de los caucheros. ¡Cuánta página en blanco, cuánta cosa que no se dijo!”, p. 384). Para construir dicha historia, el personaje-narrador se instala en el centro del espacio discursivo y se aboca a un movimiento de ficción "autobiográfica", inquiriendo sobre sí mismo y volviendo sobre su pasado y sus orígenes antes de ingresar en el "vórtice de la nada".

El movimiento discursivo y las estrategias narrativas de Arturo Cova no parecen ser sino un torbellino en torno al cual se arremolinan los personajes y sus discursos, todos envueltos en el movimiento giratorio de la vorágine textual. Como la propia vorágine en la que se halla envuelto, es decir, en esa Violencia que se apoderó de su corazón (p. 79), Arturo Cova atrae en torno suyo a aquellos seres desorientados, a quienes arrastra hacia aventuras inciertas; al hacerlo acoge y devora los demás discursos que giran a su alrededor, los asimila y hace suyos, confundiéndose así, de manera inextricable, las voces de la selva devoradora con aquella selva vertiginosa de voces, con aquel eco de "multísonas voces".

\section{De Cova a Rivera: viaje al corazón de la selva de la escritura}

En su ya clásico libro sobre las novelas fundacionales del continente, Doris Sommer (2004) destaca, en ese contexto, la excepcionalidad de la obra del colombiano, sus múltiples aristas, que resultan concomitantes con la contradictoria personalidad del protagonista y, por otra parte, ha señalado que la novela "transgrede continuamente las normas relativas al género, deconstruye las nociones de heroísmo y propiedad; y desordena la tradicional línea recta de la narración" (1987, p. 467); además, propone que una posible lectura de la novela implicaría considerar que para Cova el enemigo no es tanto el "otro", o la selva, o la mujer agresiva, sino él mismo o "al menos esa parte de sí mismo que corresponde al ideal positivista e instrumental de los padres fundadores" (p. 476). Dicha deriva puede incluso vincularse con una suerte de transformación de

\footnotetext{
${ }^{12}$ Considerando este movimiento de presentación, exposición, adaptación e incluso apropiación de otras voces realizadas por el narrador, Elzbieta Sklodowska (1995) asimila la escritura y el habla de Cova al llamado discurso heterólogo, un discurso de la otredad, elemento sustancial de la ficción testimonial.
} 
la propia escritura del abogado y escritor Rivera quien, en La vorágine, como lo ha explicado Miguel Gomes (1998), comienza a apartarse del canon modernista -que había concretado en Tierra de promisión- para adentrarse en un ejercicio mundonovista y expresionista, aunque sin apartarse del todo de sus preferencias estéticas iniciales. Un escritor entre dos aguas, entonces, con similares oscilaciones a las que presenta su narrador, que es inestable, ambiguo, fluctuante, con un doble proyecto -testimonial y literario- y una escritura que oscila entre lo lírico y lo narrativo, y que manifiesta una desconfianza tanto de la "civilización" como hacia la "barbarie". Si la intriga de la novela ofrece múltiples ejemplos de dualidades y repeticiones, una duplicidad materializada además en el marco narrativo con las figuras de Rivera "editor" y Cova "escritor", también encontraremos un fenómeno similar incluso en elementos mínimos del discurso novelesco.

De hecho, las recurrencias invaden también la escritura, ya sea en el plano de lo propiamente narrado - Cova reitera gestos y actitudes, vuelve una y otra vez sobre los mismos sucesos, aunque desde distintos ángulos-, como en el nivel de la enunciación, en particular a través de la presencia sostenida de ciertas palabras que adquieren o contienen determinado contenido simbólico, entre las que destacan, por ejemplo, "selva", "verde", "ver", "víveres", "aventura", entre otros. De acuerdo con esta particularidad, se puede proponer el esbozo de una lectura de la materia textual, lingüística, una lectura de determinadas "huellas" de lo ínfimo, del detalle, en suma, una microlectura para citar a Jean-Pierre Richard (1979) ${ }^{13}$. Se constata, como también se puede apreciar con el nombre de ciertos personajes -Arturo Cova, Ramiro Estévanez, Narciso Barrera, el viejo Silva, El Váquiro- que aquellos términos o denominaciones presentan elementos comunes: la presencia de la letra "uve" y/o de la letra "erre"; fonemas dobles, por lo demás: la "uve" porque es una letra que, al menos impresa (V), representa gráficamente un proceso de fusión y de separación y, además, porque tiene un desdoblamiento gráfico y fonético, aunque éste haya en cierto modo desaparecido, en la "b"; la "erre" porque posee una doble grafía, y una doble pronunciación, como vibrante múltiple o simple.

Al leer el texto bajo este prisma, se constata que esa "erre" y esa "uve" invaden la escritura, la modulan y modelan, emergen y comparecen en gran parte del discurso: en las disquisiciones, en las descripciones, en la narración, en documentos transcritos, en la materialidad de la historia de Arturo. Ya en el fragmento de la carta de Cova, que sirve en cierto modo de epígrafe, el poeta se caracteriza como alguien arrojado por el destino, "para que ambulara, vagabundo, como los vientos, y me extinguiera como ellos sin dejar más que ruido y desolación" (p. 77, negritas mías). La presencia de la "uve" -también de la "b"- y de la "erre" será todavía más fuerte y densa en múltiples pasajes del texto, manifestaciones textuales a las cuales habría además que añadir la de la "ese" - presente en "selva" y "Silva", por ejemplo- y su realización como "zeta" y "ce" -"Alicia", "Zoraida"-, pues en el español de América no existe una pronunciación diferenciada entre ambas. Algunos breves ejemplos (donde se destaca en negrita esta insistencia):

La visión frenética del naufragio me sacudió con una ráfaga de belleza. El espectáculo fue magnífico. La muerte había escogido una forma nueva contra sus víctimas, y era de agradecerle que nos devorara sin verter sangre, sin dar a los cadáveres livores repulsivos. (p. 233).

\footnotetext{
${ }^{13}$ Una lectura en la que incluso la más mínima unidad de sentido, como la letra, el grafema, puede decir algo de una historia particular y constituir así uno de los elementos dinámicos de una construcción escritural implicada en un proceso complejo de autofundación y de legitimación identitaria.
} 
Por primera vez, en todo su horror, se ensanchó ante mí la selva inhumana. Árboles deformes sufren el cautiverio de las enredaderas advenedizas, que a grandes trechos los ayuntan con las palmeras y se descuelgan en curva elástica [...] (p. 295).

Va para seis semanas que, por insinuación de Ramiro Estévanez, distraigo la ociosidad escribiendo las notas de mi odisea, en el libro de caja que el Cayeno tenía sobre su escritorio como adorno inútil y polvoriento. Peripecias extravagantes, detalles pueriles, páginas truculentas forman la red precaria de mi narración, y la voy exponiendo con pesadumbre, al ver que mi vida no conquistó lo trascendental y en ella todo, resulta insignificante y perecedero (p. 345).

Sin olvidar, claro está, que dichas letras, y sus sonidos, están presentes en la última frase del texto -“Los devoró la selva” (p. 385)-, en su título, La vorágine, en Eustasio Rivera, el nombre del autor, y en el del protagonista, Arturo Cova. Desde la subjetividad de este se inicia el gesto de un sujeto que cuenta su propia historia, lo que implica un acto de conocimiento y, por lo mismo, de alteridad, porque el objeto de dicho conocimiento se construye como un "otro" al que se intenta acceder para apropiárselo. La necesidad de conocerse a sí mismo, de constituirse en sujeto y asignarse existencia, sólo puede lograrse por medio de la enunciación del yo en tanto sujeto del discurso. Benveniste (1966), en "De la subjetividad en el lenguaje", se refirió a esta operación de construcción de identidad, destacando el papel fundamental del lenguaje, ya que, dijo, el individuo se constituye como sujeto en y por aquel.

Por lo mismo, esta reincidencia periódica de estas letras y sonidos interpela al lector y, por ello, hasta puede parecer legítimo preguntarse por el significado íntimo, el valor personal y único que podrían tener en relación con aquella operación constitutiva. Porque se trata de una redundancia que como hecho textual -y pensada en su totalidad y aceptando ese brote del inconsciente, tan rico y complejo, que existe en el proceso de construcción de la obra y en sus múltiples significados ${ }^{14}$, , puede adquirir una fuerza singular y dinámica, en la que encuentran un fundamento las líneas esenciales de la organización de la obra y de su discurso. Eso significa una determinación inconsciente e íntima de unos valores integrados interiormente por el autor en los que se asienta su paisaje estético original y que pueden ser atribuibles a su imaginario literario, a su "mito personal" 15 . Si, entonces y, por una parte, estas letras dobles se condicen con el múltiple carácter dual de la obra, por otra, conducen, primero, al título de la misma y, segundo, al nombre del autor, con lo cual están estableciendo y determinando un sello, una marca, un signo poético e identitario. De modo que finalmente, y de acuerdo con lo dicho, se puede apuntar que esta densa novela de "las voces de selva", es también una proliferante "selva de voces", e incluso el viaje que Rivera nos propone a la selva del corazón de su escritura.

\footnotetext{
${ }^{14}$ Los significados y valores evidenciados por este tipo de lectura son, evidentemente, tan numerosos como las obras y los autores; eso significa que un valor atribuido a una unidad de sentido dentro del sistema total de la obra vale únicamente para dicha obra y para un autor único.

${ }^{15}$ Lo del mito personal lo elaboró y expuso detalladamente Charles Mauron (1963) en sus pesquisas sobre las obras de Mallarmé, Racine y Baudelaire, entre otros. Se trata, a partir de un análisis minucioso de los textos, de discernir unas redes asociativas de ideas, de metáforas obsesivas que labran una "situación dramática" interna, personal, que a menudo tiene que ver con la elaboración previa de una figura particular; dicha situación dramática es la que él llama "el mito personal".
} 
Fernando Moreno

\section{Bibliografía}

Alegría, F. (1966). Breve historia de la novela hispanoamericana. México: Ediciones de Andrea. Bajtín, M. (1982). Estética de la creación verbal. México: Siglo XXI.

. (1989). Teoría y estética de la novela. Madrid: Taurus.

. (2012). Problemas de la poética de Dostoievski. México: Fondo de Cultura

Económica.

Bellini, G. (1986). Historia de la literatura hispanoamericana. Madrid: Castalia.

Benso, S. (1975). La vorágine: una novela de relatos. Thesaurus, 30, (2), 271-290.

Benveniste, É. (1966). Problèmes de linguistique générale. Paris: Gallimard.

Crespi, R. S. (1987). La vorágine: cincuenta años después. En M. Ordóñez (Comp.). La vorágine: Textos críticos (pp. 417-429). Bogotá: Alianza Editorial.

De Chasca, E. (1987). El lirismo en La vorágine. En M. Ordóñez (Comp.). La vorágine: Textos críticos (pp. 239-257). Bogotá: Alianza Editorial.

de León Hazera, L. (1971). La novela de la selva hispanoamericana. Nacimiento, desarrollo y transformación. Estudio estilístico. Bogotá: Instituto Caro y Cuervo.

Espinoza, G. (2000). Modernismo y modernidad en La vorágine. Prólogo a José Eustasio Rivera, La vorágine (pp. 9-22). Bogotá: Panamericana Editorial.

Ford, R. (1976). El marco narrativo de La vorágine. Revista Iberoamericana, 96-97, 573-580. https://doi.org/10.5195/REVIBEROAMER.1976.3181

Franco, J. (1987). Historia de la literatura hispanoamericana. Barcelona. Ariel.

Fuentes, C. (1969). La nueva novela hispanoamericana. México: Joaquín Mortiz.

Gálvez, M. (1990). La novela hispanoamericana (hasta 1940). Madrid: Taurus.

Genette, G. (1969). Figures II. Paris: Seuil.

Gomes, M. (1988). Quiroga, Rivera y la formación del canon mundonovista. Atenea, 477, (1), $135-162$.

Gómez, F. (2008). Emergencia del mito americano en La Vorágine. Poligramas, 30, 241-268.

González, A. (1987). Elementos hispánicos y clásicos en la caracterización de La vorágine. En M. Ordóñez (Comp.). La vorágine: Textos críticos. (pp. 191-197). Bogotá: Alianza Editorial.

Green, J. R. (1967). La estructura del narrador y el modo narrativo de La vorágine. Cuadernos Hispanoamericanos, 105, 101-107.

Gutiérrez Girardot, R. (1994). La vorágine de José Eustasio Rivera. Su significación permanente para las letras de lengua española del presente siglo. Casa de las Américas, 194, 117127.

Loveluck, J. (1968). Estudio Preliminar. José Eustasio Rivera. La vorágine (6ª ed.) (pp. 9-48). Santiago: Zig-Zag.

Martell, J. (1999). La vorágine como biografía de la escritura. Horizontes: Revista de la Universidad Católica de Puerto Rico, 41, (80), 129-61.

Mateo Palmer, M. (1988). Valor y función del mito de origen americano en La vorágine, Casa de las Américas, 167, 24-31.

Mauron, C. (1963). Des métaphores obsédantes au mythe personnel. Paris: J. Corti.

Mejías-López, A. (2006). Textualidad y sexualidad en la construcción de la selva: Genealogías discursivas en La vorágine de José Eustasio Rivera. Modern Language Notes, 121, (2), 367-90.

https://doi.org/10.1353/mln.2006.0054 
Menton, S. (1987). La vorágine: el triángulo y el círculo. En M. Ordóñez (Comp.). La vorágine: Textos críticos (pp. 199-228). Bogotá: Alianza Editorial.

Molloy, S. (1987). Contagio narrativo y gesticulación retórica en La vorágine. Revista Iberoamericana, 53, (141), 745-766. https://doi.org/10.5195/reviberoamer.1987.4388

Morales, L. (1965). La vorágine: Un viaje al país de los muertos. Anales de la Universidad de Chile, 134, 148-170. https://doi.org 10.5354/0717-8883.2012.22549 . (1992). La vorágine y la novela de caballerías. Revista Chilena de Literatura, 39, 75-96.

Neale-Silva, E. (1986). Horizonte Humano: Vida de José Eustasio Rivera. México: Fondo de Cultura Económica.

Olivera, O. (1987). El romanticismo en La vorágine. En M. Ordóñez (Comp.). La vorágine: Textos críticos (pp. 259-267). Bogotá: Alianza Editorial.

Ordóñez, M. (1987). La vorágine: Textos críticos. Bogotá: Alianza Editorial.

Oviedo, J. M. (2001). Historia de la literatura hispanoamericana 3. Postmodernismo, Vanguardia, Regionalismo. Madrid: Alianza.

Perus, F. (1988). De selvas y selváticos. Ficción autobiográfica y poética narrativa en Jorge Isaacs y José Eustasio Rivera. Bogotá: Plaza \& Janés.

Porras Collantes, E. (1968). Hacia una interpretación estructural de La vorágine. Thesaurus, 23, 241-271.

Quiroga, H. (1929, enero, 22). El poeta de la selva: José Eustasio Rivera. La Nación, Buenos Aires, pp. 17-18.

Richard, J-P. (1979). Microlectures. Paris: Seuil.

Rivera, J. E. (1990). La vorágine. Madrid: Cátedra [Edición crítica de Monserrat Ordóñez [LetrasHispánicas n³15].

Sáinz de Medrano, L. (1989). Historia de la literatura hispanoamericana (Desde el Modernismo). Madrid: Taurus.

Sklodowska, E. (1995). "Con indiscreta curiosidad les pregunté...”: El discurso heterólogo en La vorágine. Revista de Crítica Literaria Latinoamericana, 21, (41), 193-211. https://doi.org/10.2307/4530804

Sommer, D. (2004). Ficciones fundacionales: las novelas nacionales de América Latina. México: Fondo de Cultura Económica. . (1987). El género deconstruido: Cómo releer el canon a partir de La vorágine. En M. Ordóñez (Comp.). La vorágine: Textos críticos (pp. 465-483). Bogotá: Alianza Editorial.

Thomas, E. (1991). La vorágine: el marco narrativo y el retorno del héroe. Revista Chilena de Literatura, 37, 97-104.

Velasco, María Mercedes de. (1995). El mito de la Mapiripana y su valor estructural en La vorágine. Texto crítico, 1,(1), 35-56.

Walker, J. (1988). Rivera, La vorágine. London: Grant \& Cutler - Tamesis Books. 